\title{
Supplementary: Studying the Discourse on Economic Policies in India Using Mass Media, Social Media, and the Parliamentary Question Hour Data
}

\author{
Anirban Sen*, Debanjan Ghatak*, Kapil Kumar*, Gurjeet Khanuja*, Deepak Bansal*, Mehak Gupta*, \\ Kumari Rekha*, Saloni Bhogale**, Priyamvada Trivedi**, Aaditeshwar Seth* \\ Indian Institute of Technology Delhi ${ }^{*}$ and Ashoka University ${ }^{* *}$
}

\begin{abstract}
ACM Reference format:
Anirban Sen*, Debanjan Ghatak*, Kapil Kumar*, Gurjeet Khanuja*, Deepak Bansal $^{*}$, Mehak Gupta*, Kumari Rekha*, Saloni Bhogale**, Priyamvada Trivedi** $^{* *}$ Aaditeshwar Seth*. 2019. Supplementary: Studying the Discourse on Economic Policies in India Using Mass Media, Social Media, and the Parliamentary Question Hour Data. In Proceedings of ACM Conference, Washington, DC, USA, July 2017 (Conference'17), 3 pages.

https://doi.org/10.1145/nnnnnnn.nnnnnnn
\end{abstract}

\section{COVERAGE OF CONSTITUENCIES BY MASS MEDIA}

We analyze the relative coverage provided by mass media to the five constituencies of poor, middle class, corporate, informal sector, and government. The relative coverage for a constituency is calculated from the aspects belonging to the constituency, for all news-sources, across all events.

$$
\operatorname{Cov}(\text { const })=\frac{\sum_{a \epsilon \text { const }} \operatorname{count}(\text { words, a) }}{\sum_{a s p \epsilon A} \operatorname{count}(\text { words, asp })}
$$

where $\operatorname{Cov}$ (const) is the relative coverage provided to the constituency, $a$ and $a s p$ are aspects, $A$ is the set of all aspects across all events across news-sources, and count(words, $a$ ) is the total number of words across all articles (across all events, across news-sources) for aspect $a$. In table 1, we show the aspect to constituency mapping for Aadhaar (similar mappings have been obtained for all of the events). The aspect names have been assigned based on what the majority articles say about the constituency - this also gives us an idea of the aspect's overall alignment towards the constituency (pro/anti). The (aspect,constituency) scores (denoted by $U(a, c)$ in RQ-1 in the main paper) of $-1 / 0 / 1$ are assigned based on whether the product of the (aspect,constituency) score and the sentiment scores of the articles in the aspect (weighted by the coverage) yield the required overall alignment.

Permission to make digital or hard copies of all or part of this work for personal or classroom use is granted without fee provided that copies are not made or distributed for profit or commercial advantage and that copies bear this notice and the full citation on the first page. Copyrights for components of this work owned by others than ACM must be honored. Abstracting with credit is permitted. To copy otherwise, or republish, to post on servers or to redistribute to lists, requires prior specific permission and/or a fee. Request permissions from permissions@acm.org.

Conference'17, fuly 2017, Washington, DC, USA

(C) 2019 Association for Computing Machinery.

ACM ISBN 978-x-xxxx-xxxx-x/YY/MM...\$15.00

https://doi.org/10.1145/nnnnnnn.nnnnnnn

\section{ALIGNMENT OF EACH NEWS-SOURCE WITH ITS FOLLOWER COMMUNITY ON SOCIAL MEDIA}

For each news-source, we compute the JS Divergence between the distribution of its aspect coverage and that of its social media community. Table 2 depicts our findings. As we can observe, for each policy, the news-sources have a high alignment in terms of aspect coverage with their followers on social media (as seen from the low values of JS divergence). We also find this trend to be dominant even when we consider the aggregate aspect coverage distribution for mass media and social media (in the main paper). From the previous section, we find that mass media provides less coverage to the issues of the poor, when compared to the middle class and the government. Thus, we can also conclude that the follower community of these news-sources also post less content on issues related to the poor. These observations indicate strongly towards the digital divide which is evident in both mass media and social media.

\section{OVERLAP BETWEEN THE FOLLOWER COMMUNITIES OF NEWS-SOURCES}

We calculate the odds-ratio of overlap of follower communities for each pair of news-sources. The results are depicted in table 3. We find that DecH, TeleG, and NIE form very strong ties in terms of their community overlaps. On the other hand, TOI and HT are mostly outliers in this network. DecH and TeleG are believed to be pro-opposition news-sources, considering the government in power when this study was done. On the other hand, NIE is believed to be a pro-establishment news-source. We can observe that some of these findings are consistent with our PCA plot on news-sources' alignment with constituencies (in the PCA too, DecH, TeleG, and NIE form a cluster). Some of these findings are also consistent with our analysis in the previous section on coverage given by mass media to political parties (entity groups). Thus, although some of the observations on community overlap can be explained from our analysis of content (the coverage given to political parties and the alignment of news-sources towards constituencies), the observations do not fully tally. It thus raises the question that how do social media followers decide which news-sources to follow the decision seems to be depend on many factors, e.g., differences in popularity of the newspapers, and pre-conceived preferences of users, alongside the content. There is a scope for deeper research in this direction 


\begin{tabular}{|c|c|c|c|c|c|}
\hline Aspect & Poor & Middle Class & Corporate & Informal & Government \\
\hline $\begin{array}{l}\text { Requirement of Aadhaar for passport } \\
\text { and other services (concessions) }\end{array}$ & 0 & 1 & 0 & 0 & 1 \\
\hline $\begin{array}{l}\text { Fake ration cards caught due to Aadhaar } \\
\text { linkage, aiding in the good of poor and } \\
\text { middle class }\end{array}$ & 1 & 1 & 0 & 0 & 1 \\
\hline $\begin{array}{l}\text { Installation of e-pos systems for Aad- } \\
\text { haar enabled PDS causing resentment } \\
\text { among poor and middle class }\end{array}$ & -1 & -1 & 0 & 0 & 1 \\
\hline $\begin{array}{l}\text { Digitization of Aadhaar enabled em- } \\
\text { ployees' provident fund, attendance sys- } \\
\text { tems at public offices, and cashless pay- } \\
\text { ments helping the middle class }\end{array}$ & 0 & 1 & 0 & 0 & 1 \\
\hline $\begin{array}{l}\text { Requirement of Aadhaar for school ad- } \\
\text { mission and the middle class }\end{array}$ & 1 & 1 & 0 & 0 & 1 \\
\hline $\begin{array}{l}\text { BSNL linking Aadhaar with mobile } \\
\text { numbers/ number of registrations under } \\
\text { Aadhaar and the middle class }\end{array}$ & 0 & 1 & 0 & 0 & 1 \\
\hline $\begin{array}{l}\text { Implementation of Direct Benefit Trans- } \\
\text { fer Scheme }\end{array}$ & 1 & 1 & 0 & 0 & 1 \\
\hline $\begin{array}{l}\text { Aadhaar based verification for middle } \\
\text { class telecom users and data leakage } \\
\text { charges against telecom companies }\end{array}$ & 0 & 1 & -1 & 0 & 1 \\
\hline $\begin{array}{l}\text { Opening of bank accounts and financial } \\
\text { inclusion helping the poor }\end{array}$ & 1 & 1 & 0 & 1 & 1 \\
\hline $\begin{array}{l}\text { LPG Subsidy \& DBT (Direct Benefit } \\
\text { Transfer) helping the poor and middle } \\
\text { class }\end{array}$ & 1 & 1 & 0 & 0 & 1 \\
\hline $\begin{array}{l}\text { Aadhaar Enrollment of voters of elec- } \\
\text { torates }\end{array}$ & 0 & 1 & 0 & 0 & 1 \\
\hline Parliamentary debates on Aadhaar & 0 & 0 & 0 & 0 & -1 \\
\hline $\begin{array}{l}\text { Simpler forms for filing income tax re- } \\
\text { turns using Aadhaar }\end{array}$ & 0 & 1 & 0 & 0 & 1 \\
\hline $\begin{array}{l}\text { International collaborations and posi- } \\
\text { tive comments on economic growth }\end{array}$ & 0 & 0 & 1 & 0 & 1 \\
\hline $\begin{array}{l}\text { Court cases related to Aadhaar (right to } \\
\text { privacy of middle class and social wel- } \\
\text { fare schemes) castigating the govern- } \\
\text { ment }\end{array}$ & 0 & -1 & 0 & 0 & 1 \\
\hline $\begin{array}{l}\text { Aadhaar requirement for college stu- } \\
\text { dents' registration and biometrics and } \\
\text { middle class }\end{array}$ & 0 & 1 & 0 & 0 & 1 \\
\hline $\begin{array}{l}\text { Aadhar enrollment centers and middle } \\
\text { class }\end{array}$ & 1 & 1 & 0 & 0 & 1 \\
\hline
\end{tabular}

Table 1: Aspect to constituency mapping for Aadhaar: a score of -1/0/+1 has been assigned to each (aspect,constituency) combination. This matrix is denoted as $U$ in the main paper (please refer to RQ-1).

\section{COVERAGE PROVIDED TO POLITICAL PARTIES BY MASS MEDIA}

We see in figure 1 , how much coverage is given to the top three highest covered entity groups (SAD for Farmers' Protest is a political party aligned to BJP). We consider the top 100 entities with highest coverage and manually group them to their respective bins of political parties, corporate directors, and academicians. Next, we measure the deviation of the relative coverage given to an entity group by a news source from the global relative coverage across all the news-sources. Here we use statements about the entities, to see the sentiment in which the news-sources project these entities. From our analysis, we find that our data shows the nearly same alignment of the news-sources as is the public perception. Across events, NIE (pro-BJP) has given above average coverage to BJP, and 


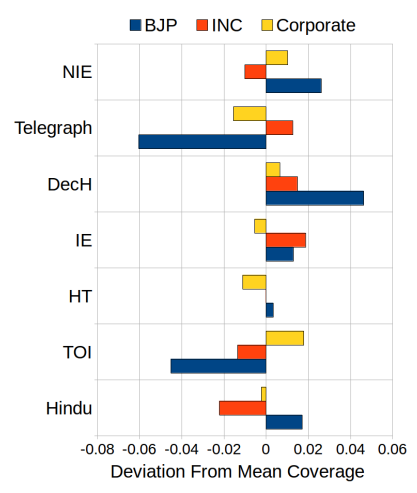

(a) Demonetization

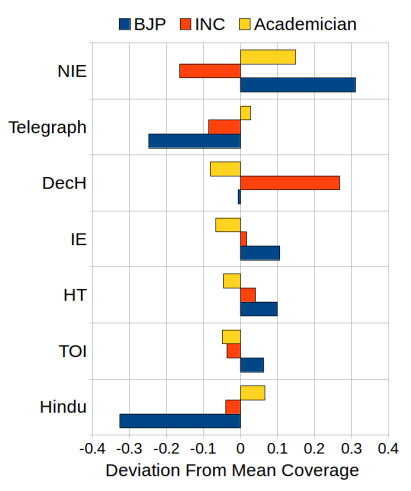

(b) Aadhaar

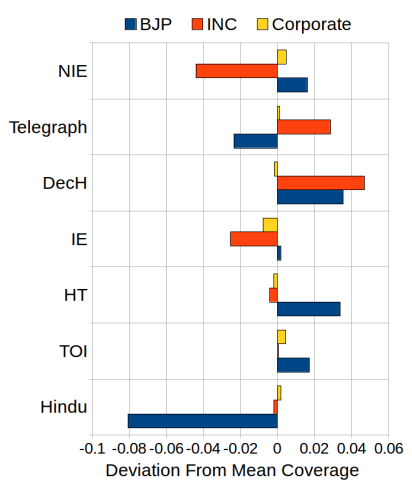

(c) GST

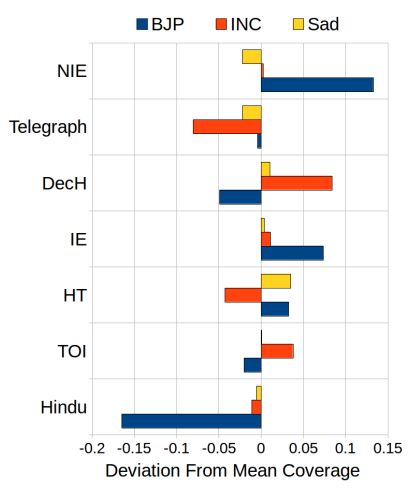

(d) Farmers' Protest ${ }^{1}$

Figure 1: Deviation of relative coverage of entity groups from their mean relative coverage across news-sources for all four policy events. Mean coverage is taken as the average coverage of an entity group across all news-sources.

\begin{tabular}{|l|c|c|c|c|}
\hline \multirow{2}{*}{ News Source } & Demonetization & Aadhaar & GST & Farmers Protest \\
\cline { 2 - 5 } & TweetFol & TweetFol & TweetFol & TweetFol \\
\hline Hindu & 0.12 & 0.08 & 0.17 & 0.15 \\
\hline HT & 0.13 & 0.03 & 0.18 & 0.07 \\
\hline IE & 0.14 & 0.03 & 0.28 & 0.08 \\
\hline NIE & 0.11 & 0.04 & 0.13 & 0.07 \\
\hline TeleG & - & 0.11 & - & 0.07 \\
\hline TOI & 0.11 & 0.04 & 0.12 & 0.04 \\
\hline DecH & 0.12 & 0.10 & 0.15 & 0.11 \\
\hline
\end{tabular}

Table 2: [RQ3] JS divergence showing difference in aspect coverage between mass media and social media: for TeleG, we could not find any tweet for Demonetization and GST

\begin{tabular}{|c|r|r|r|r|r|r|r|}
\hline & \multicolumn{1}{|c|}{ TOI } & \multicolumn{1}{c|}{ HT } & \multicolumn{1}{c|}{ Hindu } & \multicolumn{1}{c|}{ IE } & NIE & TGI & DH \\
\hline TOI & & & & & & & \\
\hline HT & 0.57 & & & & & & \\
\hline HINDU & 0.44 & 2.59 & & & & & \\
\hline IE & 0.79 & 3.71 & 6.21 & & & & \\
\hline NIE & 0.30 & 1.13 & 2.32 & 3.82 & & & \\
\hline TGI & 0.46 & 1.68 & 3.06 & 6.08 & 10.38 & & \\
\hline DH & 0.35 & 1.07 & 1.99 & 3.49 & 16.25 & 41.68 & \\
\hline
\end{tabular}

Table 3: Odds-ratio of overlap of follower community for each pair of news-sources

Telegraph (leftist) has provided below average coverage to it. For INC, we find DecH and IE (both pro-INC) giving above average coverage, and NIE giving below average coverage to it. Finally, Hindu (leftist) seems to be non-partisan, in the sense that it provides below average coverage to both parties. Our analysis thus reveals that some news-sources indeed show a bias in the coverage they give to different political parties, which also reflect their long-term or short-term political affiliations based on ownership networks of media. We plan to investigate this more closely in future work with an analysis of policy steps undertaken under different political regimes. We also find that while directors get much less coverage compared to politicians, they consistently get more coverage than academicians for all events except Aadhaar, showing affinity of news-sources to cover corporate statements instead of expert opinions. For example, academicians and corporate business-persons had coverages as $0.4 \%$ and $3.8 \%$ for Demonetization, $6.5 \%$ and $0.6 \%$ for Aadhaar, $0.28 \%$ and $0.05 \%$ for Farmers' Protest.

\section{REFERENCES}

[1] Sevanti Ninan. 2007. Headlines from the heartland: Reinventing the Hindi public sphere. Sage.

[2] Sanjeev Sharma. 2016. GST to hit consumers, unorganized jobs most. (2016). https://www.tribuneindia.com/news/nation/gst-to-hit-consumersunorganised-jobs-most/275659.html

\footnotetext{
${ }^{1}$ Directors had negligible coverage in Farmers' Protest. So we included next highest coverage entity group i.e. SAD (Shiromani Akali Dal)
} 